\title{
BIBLIOTECA DA FACULDADE
}

HORARIO - Diàriamente das 9 às $11 \frac{1}{2}$ e das 13 às 17 horas.

CATÁLOGOS - Onomástico e ideológico, em fichários à disposição do consultante.

CONSULTA - A consulta é pública, podendo ainda ser feita por correspondência, no que se refira a informações bibliográficas, sem ônus algum para o consultante. 
Quadro demunstrativo do movimento da biblioteca da faculdade de direito de s. paulo no perído de 1.0 De Janeiro a 31 de dezembro de 1933

\begin{tabular}{|c|c|c|c|c|c|c|c|c|c|c|c|c|c|c|c|c|c|c|c|c|c|c|c|c|c|c|c|c|c|c|c|c|c|}
\hline \multirow{3}{*}{ MESES } & \multicolumn{2}{|c|}{$\overline{~ L E I T O R E S}$} & \multicolumn{13}{|c|}{$\begin{array}{lllll}\text { O B R A S } & \end{array}$} & \multirow{3}{*}{\begin{tabular}{|c|} 
Total \\
de \\
obras
\end{tabular}} & \multirow{3}{*}{$\begin{array}{c}\text { Total } \\
\text { de } \\
\text { volumes }\end{array}$} & \multicolumn{8}{|c|}{$\mathrm{L} I \mathrm{~N}$ G U A S } & \multirow{3}{*}{$\mid \begin{array}{c}\text { Consul- } \\
\text { tas por } \\
\text { corres. } \\
\text { dência }\end{array}$} & \multirow{3}{*}{\begin{tabular}{|c|c} 
Mediadia \\
dijaria \\
da \\
consulta
\end{tabular} \mid} & \multirow{3}{*}{ 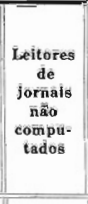 } & \multicolumn{3}{|c|}{ OBRAS ENTRADAS } & \multicolumn{2}{|c|}{$\begin{array}{c}\text { SERVICO DE } \\
\text { OFICINA }\end{array}$} \\
\hline & \multirow[b]{2}{*}{$\begin{array}{l}\text { Estra- } \\
\text { nhos }\end{array}$} & \multirow[b]{2}{*}{$\begin{array}{l}\text { Estu- } \\
\text { dantes }\end{array}$} & \multirow{2}{*}{$\frac{\mathbf{0}}{}$} & \multirow{2}{*}{$\frac{1}{\begin{array}{c}\text { Filoso- } \\
\text { fia }\end{array}}$} & \multirow{2}{*}{$\frac{2}{2}$} & \multicolumn{4}{|c|}{$3-$ Ciências jurídicas e sociais } & \multirow{2}{*}{\begin{tabular}{|c|}
4 \\
$\begin{array}{c}\text { Filo- } \\
\text { logia }\end{array}$ \\
\end{tabular}} & \multirow{2}{*}{\begin{tabular}{|c|}
5 \\
$\begin{array}{c}\text { Ciências } \\
\text { Puras }\end{array}$ \\
\end{tabular}} & \multirow{2}{*}{$\mid$\begin{tabular}{c|}
6 \\
$\begin{array}{c}\text { Ciências } \\
\text { Aplicadas }\end{array}$ \\
\end{tabular}} & \multirow{2}{*}{$\frac{7}{\substack{\text { Belas } \\
\text { Artes }}}$} & \multirow{2}{*}{8} & \multirow{2}{*}{\begin{tabular}{|c|}
9 \\
$\begin{array}{c}\text { História } \\
\text { e Geogr. }\end{array}$ \\
\end{tabular}} & & & \multirow[b]{2}{*}{ Alemão } & \multirow[b]{2}{*}{\begin{tabular}{|c|} 
Espa- \\
nhol
\end{tabular}} & \multirow[b]{2}{*}{ Francés } & \multirow[b]{2}{*}{ Ingless } & \multirow[b]{2}{*}{ Italiano } & \multirow[b]{2}{*}{ Latim } & \multirow[b]{2}{*}{$\begin{array}{c}\text { Portu- } \\
\text { guês }\end{array}$} & & & & & & & & & \\
\hline & & & & & & \begin{tabular}{|c|c|} 
Sociolo- \\
gia \\
Politica \\
$30-32$ \\
$30-32$
\end{tabular} & $\begin{array}{c}\text { Estatis- } \\
\text { ca e eco- } \\
\text { nomia } \\
31-33 \\
1-3\end{array}$ & $\begin{array}{l}\text { Direito } \\
34-35 \\
\end{array}$ & 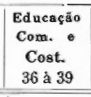 & & & & & & & & & & & & & & & & \begin{tabular}{|c|} 
Outras \\
língaas
\end{tabular} & & & & Compra & Doasă̄o & $\begin{array}{c}\text { Per- } \\
\text { mata }\end{array}$ & 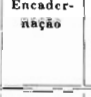 & $\begin{array}{l}\text { Recons- } \\
\text { bituisága }\end{array}$ \\
\hline 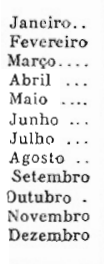 & $\begin{array}{c}- \\
-12 \\
131 \\
196 \\
206 \\
210 \\
228 \\
372 \\
262 \\
394 \\
250 \\
269\end{array}$ & $\begin{array}{r}148 \\
230 \\
600 \\
454 \\
788 \\
792 \\
371 \\
710 \\
1.144 \\
838 \\
651 \\
343\end{array}$ & $\begin{array}{r}22 \\
36 \\
82 \\
107 \\
121 \\
117 \\
1106 \\
171 \\
142 \\
222 \\
159 \\
131\end{array}$ & $\begin{array}{c}- \\
12 \\
23 \\
24 \\
41 \\
16 \\
30 \\
84 \\
35 \\
70 \\
45 \\
51\end{array}$ & $\begin{array}{r}1 \\
2 \\
17 \\
12 \\
14 \\
2 \\
12 \\
9 \\
2 \\
1.5 \\
2 \\
2 \\
6\end{array}$ & $\begin{array}{c}- \\
21 \\
55 \\
38 \\
139 \\
68 \\
101 \\
67 \\
63 \\
59 \\
58\end{array}$ & \begin{tabular}{|c}
- \\
- \\
19 \\
50 \\
30 \\
35 \\
34 \\
43 \\
41 \\
47 \\
56 \\
33
\end{tabular} & $\begin{array}{r}149 \\
177 \\
400 \\
403 \\
807 \\
1.001 \\
300 \\
812 \\
1.320 \\
1.100 \\
769 \\
499\end{array}$ & $\begin{array}{c}= \\
80 \\
75 \\
62 \\
65 \\
66 \\
56 \\
59 \\
17 \\
3 \\
7\end{array}$ & $\begin{array}{r}2 \\
- \\
9 \\
6 \\
9 \\
21 \\
14 \\
35 \\
17 \\
37 \\
31 \\
44\end{array}$ & $\begin{array}{r}- \\
1 \\
4 \\
7 \\
9 \\
3 \\
12 \\
11 \\
3 \\
3 \\
8 \\
2 \\
2\end{array}$ & \begin{tabular}{r|}
1 \\
2 \\
4 \\
2 \\
3 \\
2 \\
5 \\
1 \\
-9 \\
-9 \\
9
\end{tabular} & $\begin{array}{r}\text { 三 } \\
3 \\
3 \\
-1 \\
-3 \\
4 \\
5 \\
5 \\
- \\
-\end{array}$ & $\begin{array}{c}3 \\
6 \\
32 \\
40 \\
54 \\
22 \\
52 \\
69 \\
50 \\
40 \\
33 \\
11\end{array}$ & $\begin{array}{c}-6 \\
6 \\
93 \\
23 \\
26 \\
19 \\
54 \\
58 \\
31 \\
32 \\
14 \\
25\end{array}$ & $\begin{array}{r}148 \\
242 \\
771 \\
811 \\
1.217 \\
1.243 \\
1.243 \\
7.73 \\
1.4738 \\
1.660 \\
1.619 \\
1.190 \\
870\end{array}$ & $\mid \begin{array}{r}213 \\
335 \\
1.076 \\
1.166 \\
1.665 \\
1.635 \\
1.539 \\
1.098 \\
1.985 \\
2.208 \\
2.197 \\
1.623 \\
1.245 \\
1.245\end{array}$ & $\begin{array}{l}E \\
E \\
\bar{E} \\
\bar{E} \\
16 \\
1 \\
2 \\
-1 \\
{ }_{1}\end{array}$ & $\begin{array}{l}5 \\
9 \\
21 \\
31 \\
45 \\
14 \\
36 \\
73 \\
45 \\
23 \\
28 \\
18\end{array}$ & $\begin{array}{l}38 \\
34 \\
204 \\
2007 \\
1183 \\
167 \\
1187 \\
2277 \\
2366 \\
286 \\
157 \\
153\end{array}$ & \begin{tabular}{|r|}
- \\
\\
12 \\
3 \\
10 \\
10 \\
7 \\
3 \\
32 \\
14 \\
55 \\
13 \\
23 \\
23
\end{tabular} & \begin{tabular}{c|}
4 \\
10 \\
47 \\
32 \\
33 \\
19 \\
35 \\
64 \\
45 \\
30 \\
27 \\
24
\end{tabular} & $\begin{array}{c}5 \\
19 \\
9 \\
3 \\
27 \\
2 \\
15 \\
15 \\
24 \\
8 \\
14 \\
=\end{array}$ & $\begin{array}{r}95 \\
153 \\
455 \\
535 \\
937 \\
9.038 \\
1.031 \\
561 \\
994 \\
1.430 \\
1.251 \\
935 \\
650\end{array}$ & $\mid \begin{array}{c}1 \\
1 \\
-^{2} \\
E^{2} \\
{ }^{3} \\
{ }^{1} \\
=\end{array}$ & $\begin{array}{l}\text { 三 } \\
\text { 三 } \\
2 \\
2 \\
4 \\
6 \\
13 \\
22 \\
12\end{array}$ & \begin{tabular}{l|l}
6 & 6 \\
10 & 30 \\
25 & \\
38 & \\
42 & \\
23 & \\
41 & \\
55 & \\
40 & \\
25 &
\end{tabular} & $\begin{array}{l}120 \\
1220 \\
2230 \\
2255 \\
473 \\
421 \\
471 \\
5399 \\
4999 \\
5396 \\
293 \\
293\end{array}$ & $\begin{array}{l}39 \\
53 \\
28 \\
58 \\
53 \\
53 \\
52 \\
43 \\
33 \\
31 \\
34 \\
31 \\
20\end{array}$ & $\begin{array}{l}34 \\
34 \\
32 \\
40 \\
144 \\
244 \\
136 \\
3320 \\
3138 \\
238 \\
83\end{array}$ & $\begin{array}{l}38 \\
25 \\
41 \\
17 \\
13 \\
13 \\
23 \\
50 \\
58 \\
21 \\
12 \\
12 \\
34\end{array}$ & $\begin{array}{l}\text { 三 } \\
\text { 三 } \\
\text { F1 }_{91} \\
77 \\
83 \\
79 \\
79\end{array}$ & $\begin{array}{l}\text { 三 } \\
\text { 三 } \\
\bar{E} \\
{ }_{29}^{29} \\
16 \\
6 \\
32 \\
41\end{array}$ \\
\hline Totais .. & 2.630 & 6.769 & 1.416 & 431 & 94 & 669 & 388 & 8.007 & 490 & 225 & 63 & 41 & 25 & 412 & 297 & 12.159 & 16.356 & 20 & 348 & 2.066 & 181 & 370 & 126 & 9.034 & 11 & 61 & - & 4.322 & 525 & 1.805 & 360 & 409 & 140 \\
\hline
\end{tabular}

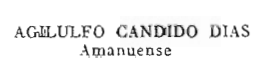


RELAÇÃO DOS LIVROS ENTRADOS NO MESMO PERIODO.

\begin{tabular}{|c|c|c|c|c|c|c|c|c|c|c|c|c|c|c|c|c|c|c|c|c|}
\hline \multirow[b]{2}{*}{ MESES } & \multirow[b]{2}{*}{ Compra } & \multirow[b]{2}{*}{ Doação } & \multirow[b]{2}{*}{ Permuta } & \multirow[b]{2}{*}{$\begin{array}{c}\text { Revista } \\
\text { Fasc. }\end{array}$} & \multicolumn{10}{|c|}{ C LAS SE } & \multirow[b]{2}{*}{$\begin{array}{l}\text { Espa- } \\
\text { nhol }\end{array}$} & \multirow[b]{2}{*}{ Francês } & \multirow[b]{2}{*}{ Inglês } & \multirow[b]{2}{*}{ Italiano } & \multirow[b]{2}{*}{$\begin{array}{l}\text { Portu- } \\
\text { guês }\end{array}$} & \multirow[b]{2}{*}{$\begin{array}{c}\text { Outras } \\
\text { linguas }\end{array}$} \\
\hline & & & & & 0 & 1 & 2 & 3 & 4 & 5 & 6 & 7 & 8 & 9 & & & & & & \\
\hline Janeiro... & 39 & 34 & 38 & 81 & 38 & 1 & 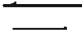 & 34 & 2 & 1 & 4 & 二 & 3 & 27 & 3 & 11 & 3 & 1 & 93 & - \\
\hline Fevereiro & 53 & 6 & 25 & 24 & 9 & 4 & 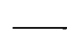 & 65 & $\longrightarrow$ & + & 1 & 1 & 1 & 3 & 5 & 14 & 1 & 3 & 58 & 2 \\
\hline Março.... & 28 & 32 & 41 & 44 & 12 & - & - & 68 & $\longrightarrow$ & $\longrightarrow$ & 3 & - & 10 & 8 & 11 & 23 & 6 & 8 & 52 & \\
\hline Abril $\ldots$ & 58 & 40 & 17 & 38 & 9 & - & - & 80 & 1 & 1 & 4 & 1 & 5 & 7 & 14 & 15 & 7 & 21 & 57 & - \\
\hline Maio .... & 93 & 144 & 13 & 56 & 47 & 6 & 2 & 113 & 1 & 一 & 4 & 3 & 49 & 23 & 4 & 98 & 3 & 7 & 137 & 1 \\
\hline Junho ... & 53 & 244 & 13 & 133 & 52 & 12 & 3 & 110 & 1 & 2 & 1 & 1 & 21 & 106 & 24 & 41 & 41 & 7 & 194 & 3 \\
\hline Julho $\ldots$ & 42 & 136 & 28 & 6 & 10 & 5 & 6 & 147 & 1 & 2 & 1 & - & 17 & 17 & 43 & 30 & 17 & 8 & 106 & 1 \\
\hline Agosto .. & 43 & 320 & 50 & 11 & 27 & 11 & 13 & 238 & 2 & 8 & 9 & 3 & 52 & 58 & 27 & 96 & 25 & 46 & 219 & 1 \\
\hline Setembro & 31 & 369 & 68 & 101 & 82 & - & - & 358 & - & 2 & - & $\ldots$ & 17 & 4 & 53 & 61 & 3 & 15 & 330 & 2 \\
\hline Outubro . & 34 & 137 & 21 & 16 & 23 & 7 & 10 & 106 & 1 & 8 & 2 & - & 24 & 7 & 14 & 29 & 6 & 3 & 132 & 4 \\
\hline Novembro & 31 & 251 & 12 & 10 & 20 & 2 & - & 183 & - & 3 & 5 & - & 62 & 10 & 10 & 17 & 5 & 3 & 259 & 1 \\
\hline Dezembro & 20 & 83 & 34 & 34 & 14 & - & - & 66 & 1 & 1 & 3 & - & 36 & 2 & 7 & 17 & 2 & 5 & 92 & 二 \\
\hline Total ... & 525 & 1.805 & 346 & 554 & 343 & 58 & 34 & 1.570 & 10 & 28 & 37 & 9 & 297 & 272 & 218 & 452 & 119 & 130 & 1.729 & 15 \\
\hline
\end{tabular}

Total geral das obras entradas: 2.676 . 